\title{
QUEM SOMOS NÓS? PERFIL DA COMUNIDADE ACADÊMICA BRASILEIRA NA EDUCAÇÃO EM ASTRONOMIA
}

\section{Who are we? The Brazilian academic community's profile in Astronomy education}

\author{
Marcos Daniel Longhini ${ }^{1}$. Hanny Angeles Gomide ${ }^{2}$. \\ Telma Cristina Dias Fernandes ${ }^{3}$
}

Resumo: Este artigo tem como objetivo elucidar qual o perfil da comunidade acadêmica brasileira que atuou ou ainda atua na Educação em Astronomia. Apresenta um breve retrospecto histórico que revela como a Astronomia vem ganhando terreno no cenário nacional e, neste bojo, os trabalhos voltados para o campo da Educação em Astronomia. Os dados foram obtidos por meio dos currículos da Plataforma Lattes, dos pesquisadores envolvidos com Astronomia, e revelaram que, dos 1072 envolvidos, 187 desenvolvem atividades nesse campo. Destes, a formação acadêmica ocorreu, prioritariamente, na região Sudeste e, nesta mesma região, atuam, sobretudo, em universidades. Há prevalência de graduados em Física, com pós-graduação em Física e Astronomia, especialmente quando atuam na divulgação científica, e predominância de doutores em Educação, no campo da pesquisa e produção bibliográfica em Educação em Astronomia.

Palavras-chave: Educação em Astronomia. Pesquisa acadêmica. Comunidade acadêmica. Plataforma Lattes.

\begin{abstract}
This article aims at clarifying the profile of the academic community who has worked on Astronomy Education. It presents a short background on the field which reveals that the interest in the area has increased in the national scenario, as well as research on Astronomy Education. The data were obtained from the researches' Lattes Platform résumé' who are involved in astronomy studies, and revealed that of 1,085 subjects involved, 187 have activities in this specific field. Most of them graduated from Brazilian southeastern universities where they have also taught. It was also observed that the number of researchers who have worked on science communication have graduated in Physics and their $\mathrm{PhD}$ degrees are in Physics and Astronomy. On other hand the ones who have dealt with research and production in Astronomy Education graduated in Physics but their $\mathrm{PhD}$ was in the educational area.
\end{abstract}

Keywords: Astronomy Education. Academic research. Academic community. Lattes Platform.

\footnotetext{
${ }^{1}$ Universidade Federal de Uberlândia (UFU), Faculdade de Educação, Avenida João Naves de Ávila, 2121, campus Santa Mônica, sala 1G-105, Uberlândia, MG, Brasil. E-mail: mdlonghini@faced.ufu.br

${ }^{2,3}$ Universidade Federal de Uberlândia (UFU), Programa de Pós-Graduação em Educação, Uberlândia, MG, Brasil.
} 
Longhini, M. D.; Gomide, H. A.; Fernandes, T. C. D.

\section{Introdução}

Temos percebido um crescente número de trabalhos, apresentados em eventos científicos e em revistas especializadas, que tratam de temáticas afeitas à Educação em Astronomia, como: os que focam no ensino e aprendizagem, em espaços formais e não formais (ELIAS; AMARAL; ARAÚJO, 2007; VALENTE, 2007, entre outros); os relativos à formação de professores para o ensino de Astronomia (LANGHI, 2004; LONGHINI, 2009, entre outros), a metodologias de ensino e recursos didáticos (AMARAL, 2008 entre outros), a título de exemplo. Também temos notado que tais trabalhos são oriundos de diferentes partes do país, de distintas instituições de ensino e pesquisa, com presença constante de alguns pesquisadores, que, há algum tempo, têm realizado investigações em torno desse campo específico de estudo.

A partir de tal cenário, este trabalho propõe responder à seguinte questão central: qual o perfil da comunidade acadêmica brasileira que atuou ou ainda atua na Educação em Astronomia? Para responder a este questionamento, o desdobramos em subquestões: como esses pesquisadores estão distribuídos pelo território nacional? Qual formação possuem, seja em nível de graduação e de pós-graduação? Em que época realizaram seus estudos? A que tipo de instituição estão vinculados? Quantos profissionais realizam atividades de extensão acerca do tema, e qual o seu perfil? Quantos desenvolvem atividades de pesquisa na área, e qual o seu perfil?

Estruturamos o presente artigo em quatro momentos. No primeiro, trazemos um breve retrospecto a respeito do surgimento, no Brasil, dos estudos de Astronomia, encaminhando nossa trajetória no sentido de apontar como as primeiras iniciativas em Educação em Astronomia surgiram no cenário brasileiro e vêm se ampliando no decorrer do tempo.

No segundo momento, fizemos a descrição dos procedimentos metodológicos adotados nesta pesquisa, os quais permitem, ao leitor, compreender como os dados foram obtidos e analisados. No terceiro, apresentamos os dados expressos na forma de gráficos, seguidos de sua análise. Por fim, no quarto momento, expomos nossas considerações a respeito da questão central levantada, tomando por base as subquestões.

\section{Da história da Astronomia, no Brasil, às ações na Educação em Astronomia}

O emprego de elementos do campo da Astronomia, no Brasil, provavelmente, é mais antigo que a própria nação. Segundo Faria et al. (1987), isso vem ocorrendo por meio dos índios que aqui viviam. De maneira formal, a primeira atividade astronômica em território nacional ocorreu em início de 1500, que foi a determinação, por meio de um astrolábio, da latitude das terras brasileiras. Isso foi feito por Mestre João, que acompanhava Pedro Álvares Cabral em sua viagem à nova terra (MORAES, 1984).

Após tal fato, por quase um século e meio, de acordo com Moraes (1984), os portugueses não se interessaram por investir em nada relacionado a estudos científicos na região recém-conquistada. Segundo o mesmo autor, foi somente com a chegada dos holandeses no Nordeste brasileiro que tais estudos tiveram início, uma vez que eles levavam, em suas viagens, recursos para estudarem as novas regiões subjugadas. Conforme citam Faria et al. (1987), foi o príncipe holandês, Maurício de Nassau, quem instalou, no Brasil, o primeiro observató- 
Quem somos nós? Perfil da comunidade acadêmica ...

rio astronômico, em Pernambuco, em 1639. Conforme Moraes (1984), naquele ano ocorreram, de modo sistemático, as primeiras observações meteorológicas e astronômicas de todo o hemisfério austral. Naquela época, o Brasil colonial assistiu a um período de oito anos de atividade científica, desenvolvida por um grupo de pessoas dedicadas à ciência, vindas a pedido do Conde de Nassau.

Durante, aproximadamente, os próximos cem anos subsequentes, a Astronomia restringiu-se aos ensinamentos dos jesuítas, os primeiros a lecionarem esta ciência no Brasil (FARIA et al., 1987). Segundo Moraes (1984), nesse período, a ênfase era no desenvolvimento de trabalhos astronômicos, cartográficos e geodésicos, uma vez que havia interesses em torno dos tratados estabelecidos entre Portugal e Espanha na divisão das novas terras. Exemplo disso foi a vinda, a pedido de D. João VI, em 1753, de Inácio Szentmartonyi, astrônomo régio, para auxiliar nas demarcações dos limites entre as terras portuguesas e espanholas. Com base em tais tipos de trabalho, os jesuítas, no curso das missões, iam ajudando a compor o mapa do território brasileiro.

Em 1808, a vinda da côrte portuguesa para o Brasil fez com que uma série de medidas fossem tomadas, dentre elas, a fundação da Academia Real Militar, que teve importante papel na cultura científica local (MORAES, 1984). Também, segundo o mesmo autor, pelas necessidades de navegação, de estudos geográfico-geodésico-astronômicos, além de motivos militares, a corte portuguesa, em 1827, criou um observatório astronômico no Rio de Janeiro, então, capital do Império. Conforme afirmam Faria et al. (1987), após a Proclamação da República, em 1889, esse observatório passou a ser denominado 'Observatório Nacional' (ON), preservando, até hoje, este nome.

No final do século XIX, como esclarecem os mesmos autores, um outro observatório foi instalado no Rio de Janeiro, o qual está localizado no Morro do Valongo, ligado, atualmente, à Universidade Federal do Rio de Janeiro (UFRJ). Trata-se da primeira instituição nacional a oferecer um curso de graduação em Astronomia. Segundo Arany-Prado e Gonzalez (1997), este curso teve início no ano de 1958, e fazia parte da Faculdade Nacional de Filosofia (FNFi), à época, pertencente à antiga Universidade do Brasil, incorporada, a partir da Reforma Universitária de 1967, à UFRJ.

Por volta do mesmo período, na cidade de São Paulo, com a já criada Escola Politécnica, em 1893, começaram os primeiros cursos de Astronomia, sobretudo voltados à formação de profissionais com incumbência de realizar levantamentos geográfico-geodésico-astronômicos (MORAES, 1984). Conforme o mesmo autor, em 1910, teve início a construção do Observatório Oficial do Estado, que, com a expansão de suas atividades, em 1932, ganhou novas instalações, as quais pertencem, atualmente, ao Instituto Astronômico e Geofísico da Universidade de São Paulo (IAG-USP). Trata-se da segunda instituição nacional a oferecer estudos em nível de graduação em Astronomia, com início da primeira turma de estudantes em 2009 (DAMINELI, 2008). Há algumas outras instituições brasileiras que, historicamente, têm desenvolvido atividades relacionadas à Astronomia, especialmente, em estudos de pósgraduação, voltados à pesquisa, como, por exemplo: o Instituto Tecnológico de Aeronáutica (ITA), o Instituto Nacional de Pesquisas Espaciais (INPE), a Universidade Federal de Minas Gerais (UFMG), por meio do Observatório da Serra da Piedade, o Departamento de Astrono- 
mia da Universidade Federal do Rio Grande do Sul (UFRGS) e o Laboratório Nacional de Astrofísica (LNA).

Segundo Arany-Prado e Gonzalez (1997), a primeira dissertação de mestrado em Astronomia, no Brasil, data de 1969, realizada no ITA, o que nos leva a verificar que, mesmo no campo das pesquisas específicas em Astronomia, trata-se de uma área relativamente recente no cenário nacional. Para as autoras, o início de seu desenvolvimento ocorreu, mais expressivamente, a partir da década de 1970, com a implantação da pós-graduação. De acordo com Damineli e Steiner (2010), nos trinta anos seguintes, ou seja, até o ano 2000, a taxa média de aumento anual de artigos publicados em Astronomia foi de 11,4\%, e, nos oito anos seguintes, foi de $2,3 \%$.

No cenário que começava a se delinear, há cerca de quarenta anos, em 1974, foi fundada a Sociedade Astronômica Brasileira (SAB), com sede no Observatório de São Paulo (FARIA et al., 1987), a qual mantém suas atividades até hoje. Conforme Bretones e Megid Neto (2006), a SAB realiza reuniões anuais, com cerca de quatrocentos participantes em cada edição, as quais se constituem em fóruns para discutir temas e pesquisas relativas à Astronomia, que ocorrem por meio de conferências, palestras, exposições, entre outros.

Conforme os mesmos autores, em 1993, foi criada, no âmbito da SAB, uma comissão voltada para o ensino de Astronomia, denominada Comissão de Ensino da SAB (CESAB). Na atualidade, ela é chamada Comissão de Ensino e Divulgação da SAB. Estudo realizado por esses autores, a partir das atas dos encontros da referida sociedade, no período de 1977 a 2003, demonstrou que tem havido um crescente número de trabalhos na área de Educação, sobretudo a partir de 1993, ano da criação da citada comissão de ensino. Para os autores, isso revela o incremento que esse campo específico de estudo tem sofrido, que dentre outros fatores, na opinião deles, pode ter sido provocado pelas preocupações, desde os anos de 1980, de vários estados e municípios, em incorporar temas de Astronomia em seus programas curriculares, além da publicação, em 1997, dos Parâmetros Curriculares Nacionais, os quais também trazem aspectos referentes ao assunto.

O que temos verificado é que a divulgação de pesquisas em Educação em Astronomia também tem estado presente em outros eventos científicos. Como lembram Langhi e Nardi (2009a), esses trabalhos têm sido publicados: nos Encontros Nacionais de Pesquisa em Ensino de Ciências (ENPEC), desde 1997 até hoje; nos Encontros de Pesquisa em Ensino de Física (EPEF), desde 1986 até hoje; nos Simpósios Nacionais de Ensino de Física (SNEF), desde 1970 até hoje; além dos encontros Nacionais de Didática e Prática de Ensino (ENDI$\mathrm{PE}$ ), desde 1982 até hoje. Além das reuniões da SAB, segundo os autores, os trabalhos também se mostram presentes nos eventos específicos em Astronomia e Educação em Astronomia, como: nos Encontros Nacionais de Astronomia (ENAST), desde 1998 até hoje; nos Encontros Brasileiros para o Ensino de Astronomia (EBEA), cujo início foi em 1996, com oito versões realizadas; e nas reuniões anuais da Associação Brasileira de Planetários (ABP), desde 1996 até hoje; e os Encontros Regionais de Ensino de Astronomia (EREA), desde de 2009 até hoje. Destacamos, ainda, a realização, em 2011, do I Simpósio Nacional de Educação em Astronomia (SNEA), no Rio de Janeiro, também com apresentações de pesquisas.

Em investigação realizada por Castro, Pavani e Alves (2009), a respeito de trabalhos voltados ao Ensino de Astronomia, nos encontros realizados pela Sociedade Brasileira de Física (no período de 1993 a 2009), e nas reuniões da SAB (no período de 2001 a 2009), os 
Quem somos nós? Perfil da comunidade acadêmica ...

resultados mostram crescente interesse por esse campo específico de estudo, relevado, sobretudo, a partir do ano 2000.

Em pesquisa realizada por Bretones e Megid Neto (2005), mediante teses e dissertações relativas ao ensino de Astronomia defendidas no Brasil, os dados indicam que o primeiro trabalho nessa linha ocorreu em 1973, mas a preocupação com esse campo específico de estudo, no conjunto da produção da pós-graduação brasileira, começou a ganhar força a partir da segunda metade da década de 1990.

Há vários trabalhos que evidenciam como as temáticas voltadas, especificamente, ao campo da Educação em Astronomia estão presentes, não somente, em eventos científicos que têm ocorrido desde a década de 1970, como, também, nos periódicos da área de ensino. Pesquisa realizada por Iachel e Nardi (2010), em periódicos nacionais na área de ensino de Física, de 1990 a 2008, revela crescimento de trabalhos em torno do tema, especialmente, a partir de 2000, que, para os autores, significa gradual consolidação da área. Langhi e Nardi (2011), em estudo com periódicos da área de Ensino de Ciências, publicados no período de 1985 a 2008, encontraram um total de 95 artigos, distribuídos em seis diferentes revistas, o que também indica a constante presença de pesquisas nos periódicos.

Na mesma direção, Marrone Júnior e Trevisan (2009), a partir de um estudo sobre a produção acadêmica em Astronomia e Ensino de Astronomia, divulgada em periódicos de Ensino de Ciências, apontam que tem havido um movimento no sentido de constituição de uma área de Ensino de Astronomia no Brasil, apesar de ainda fortemente englobada à área de ensino de ciências. Destacam-se, segundo os mesmos autores, os esforços dos pesquisadores que começam a se reunir em pequenos grupos, buscando dar maior visibilidade aos trabalhos em torno do tema, exibidos na criação de periódicos, como, por exemplo, a Revista Latinoamericana de Educação em Astronomia (RELEA), lançada em 2004, num contexto ainda carente de periódicos na área, conforme Langhi e Nardi (2009b).

No cenário brasileiro, podemos elencar, ainda, a presença de espaços, conforme esclarecem Langhi e Nardi (2009b), nos quais se realizam atividades de ensino e de divulgação, como: os observatórios astronômicos, os planetários, os museus e os centros de Ciências. Especificamente, na divulgação em Astronomia, Linhares e Nascimento (2009) indicam que há 151 desses espaços espalhados pelo território nacional, sendo sua maior presença na região Sudeste, com quase $60 \%$ do total. Ressalta-se, ainda, que, em torno de dois terços deles, são públicos ou vinculados a instituições públicas de ensino. Em levantamento que realizamos no portal dos Observatórios e Planetários do Brasil, organizado por Varella e Oliveira (2010, 2012), verificamos que, do total de observatórios oficiais existentes no país, em data de 31/ 12/2010, 64,6\% deles localizam-se na região Sudeste, sendo 35,4\% somente no estado de São Paulo. Em relação aos planetários, em data de 22/4/2012, o portal registra que 51,8\% deles estão também na região Sudeste.

Em síntese, percebemos que a Astronomia teve início tímido no decorrer do processo de constituição do país, ganhando maior evidência no âmbito da formação de profissionais, assim como na pesquisa, em meados da década de 1970. Também nessa mesma década, surgia a primeira investigação no campo da Educação em Astronomia, sendo que novas pesquisas vêm ganhando evidência, mais fortemente, a partir da década de 1990, com maior destaque desde a primeira década de século XXI, conforme demonstram estudos sobre eventos e periódicos nos quais elas são divulgadas. 


\section{Procedimentos metodológicos da pesquisa}

De modo a compormos o conjunto dos dados desta pesquisa, recorremos aos currículos dos pesquisadores, sujeitos desta investigação. A escolha por esta fonte deu-se por entendermos que se trata de um documento que descreve e explicita a trajetória acadêmica do pesquisado.

Os currículos que serviram de dados para esta pesquisa foram aqueles disponibilizados na Plataforma Lattes, do Conselho Nacional de Pesquisa (CNPq). Investigações em outras áreas foram realizadas, usando da mesma base, como as de Silva et al. (2009), Barbosa, Dal Sasso e Berns (2009) e Pepe et al. (2010), por exemplo.

A Plataforma Lattes é uma base de dados criada em agosto de 1999, usada como padrão nacional para registrar a vida atual e pregressa de estudantes e pesquisadores de todo o país, além de ser empregada como elemento para avaliar pleitos de financiamento na área de Ciência e Tecnologia, o que revela sua confiabilidade e abrangência ${ }^{4}$ (LANE, 2010). Quando os pesquisadores disponibilizam seus dados na plataforma, eles tornam-se públicos, uma vez que podem ser acessados por qualquer pessoa por meio do portal específico ${ }^{5}$. Segundo Lane (2010), a base de dados da Plataforma Lattes possui 1.6 milhões de pesquisadores e algo em torno de quatro mil instituições cadastradas.

Os currículos colocados à disposição apresentam informações organizadas em: Dados gerais; Projetos; Produção bibliográfica; Produção técnica; Orientações; Produção cultural; Eventos e Bancas. Para cada item acrescentado no momento de criar ou atualizar o currículo, o pesquisador insere palavras-chave que caracterizarão a produção adicionada.

A Plataforma Lattes permite que os currículos sejam localizados por meio de um sistema de recuperação, que pode ser por busca simples ou por busca avançada. A busca também pode ser realizada pelo nome do pesquisador ou com base no assunto de interesse. Em ambos os casos, podem ser aplicados diferentes filtros, conforme o interesse do usuário.

Quando a busca pelos currículos for feita por assunto, a palavra ou expressão inserida irá se identificar com as palavras-chave que os pesquisadores adicionaram às suas respectivas produções. De acordo com Silva e Smit (2009), as palavras-chave servem para representar uma temática presente no documento, e elas funcionam como um recurso para a recuperação das informações, o que permite proporcionar estudos métricos da produção científica brasileira, como é o caso desta pesquisa.

Ainda, conforme os mesmos autores, não há orientações específicas para o usuário da Plataforma Lattes no momento de classificar sua produção com as palavras-chave, como, por exemplo, dispor daquelas que seus parceiros de área têm mais frequentemente usado. Isso faz com que haja uma pulverização de termos empregados, o que dificulta a recuperação da informação pelo sistema. Tomando por base tal informação, optamos pela palavra-chave Astronomia, entendendo que ela é a mais genérica e que engloba todo tipo de produção na área, inclusive, na Educação em Astronomia.

${ }^{4}$ Informações disponíveis em: http://www.cnpq.br/> e <http://lattes.cnpq.br/>. Acesso em: 03 ago. 2011.

${ }^{5}$ Informações disponíveis em: http://www.cnpq.br/> e <http://lattes.cnpq.br/>. Acesso em: 03 ago. 2011. 
Quem somos nós? Perfil da comunidade acadêmica ...

Imprimimos, em nossa busca, alguns outros critérios, como selecionar somente documentos de pesquisadores com doutorado completo, entendendo que, a partir desta etapa, eles ganham autonomia para criar grupos de pesquisa, coordenar seus projetos e orientar em pós-graduação stricto sensu, por exemplo. Trabalhamos com a busca avançada, ou seja, com currículos que tenham a frase exata Astronomia, conforme ilustra a Figura 1.

Figura 1. Tela que ilustra o sistema de busca avançada por assunto

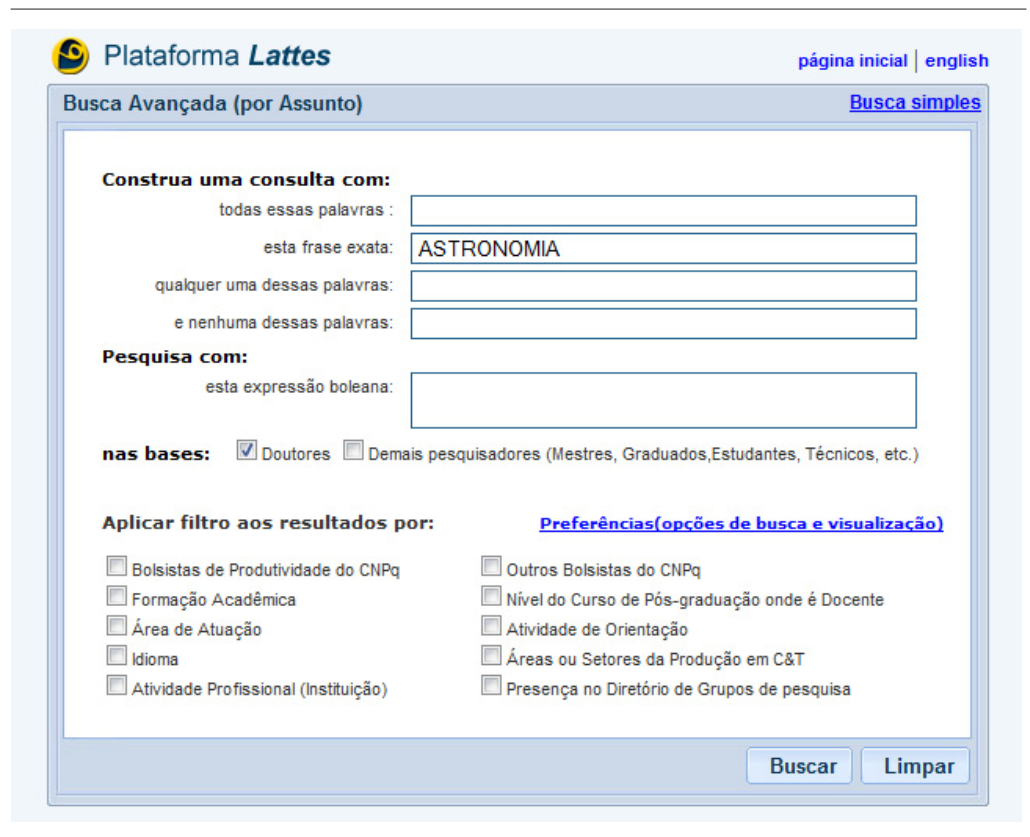

Fonte: PLATAFORMA Lattes (2011).

Entendemos que o fato de a palavra Astronomia estar presente em um determinado currículo não é indício de que o pesquisador possui algum tipo de produção, especificamente, em Educação em Astronomia, podendo dedicar-se a outros campos específicos de estudo dessa ciência. Portanto, no momento seguinte à recuperação dos currículos, partimos para sua análise individualizada.

Descrevemos os critérios, por nós adotados, para a inclusão ou exclusão de currículos selecionados no conjunto dos pesquisadores. Excluímos, dos dados contabilizados, os pesquisadores que não apresentavam nenhum tipo de produção em interface com a Educação em Astronomia, além daqueles que possuem currículos cadastrados, mas que não atuam no território brasileiro, uma vez que nosso foco foi a comunidade nacional. Portanto, como critérios de inclusão, consideramos os que comprovam que o profissional possui produção no campo específico da Educação em Astronomia. Sendo assim, entendemos que o pesquisador precisa explicitar, pelo menos, um dos seguintes elementos em seu currículo: 
a) apresentar projeto, concluido ou em andamento, relacionado com a Educação em Astronomia: um projeto registrado na plataforma pode ser de pesquisa, extensão ou desenvolvimento. Tomamos como válidas todas as modalidades. Entendemos que a participação em um projeto, seja como membro ou coordenador, seja financiado por agência de fomento ou não, revela envolvimento com o campo específico de estudo, uma vez que se entende que, para dele participar, o pesquisador terá de despender tempo de trabalho, conhecimento, leituras, coleta de dados, estratégias de divulgação e outras tarefas pertinentes;

b) ser autor on coantor de livro, capitulo de livro ou artigo cientifico publicado com temática relativa à Educação em Astronomia: os resultados das investigações são, via de regra, divulgados em livros e periódicos científicos. Entendemos que, se o pesquisador apresenta trabalho de sua autoria ou coautoria, deve ter envolvimento com a temática de investigação, mesmo que desenvolva, paralelamente, trabalhos em outras áreas;

c) orientar ou ter orientado iniciação científica e/ ou mestrado e/ ou doutorado com temática relativa à Educação em Astronomia: a atividade de orientar uma pesquisa, seja de um aluno iniciante, ou em um programa de pós-graduação stricto sensu, requer do professor um período de vários meses em torno de um trabalho, mesmo que ele seja de exclusividade do pós-graduando. Entendemos que exige do orientador conhecimento no campo em estudo;

d) ser autor de dissertação de mestrado e/ ou tese de doutorado com temática relacionada à Educação em Astronomia: tais trabalhos podem ter sido realizados no âmbito de programas de pós-graduação em Astronomia, Física, Ensino de Ciências, Educação, no interior de suas mais diferentes linhas de pesquisa ou áreas de concentração, e precisam mostrar relação com a temática em questão.

\section{Dados obtidos e análise}

A partir da busca realizada, encontramos, em 04 de outubro de 2011, 1.072 currículos, os quais foram recuperados e gravados individualmente. Destes, excluímos dois, por se tratarem de pesquisadores estrangeiros e que não atuam no Brasil. Após isso, efetuamos a triagem em cada um dos currículos, obedecendo aos critérios previamente apontados, o que nos resultou em 187 pesquisadores selecionados, ou seja, 17\% do total. Esse foi o nosso público-alvo, o qual nos indica a parcela de envolvimento desses profissionais nas questões educacionais.

De certa maneira, tal resultado vai na direção do obtido pelo censo astronômico realizado, em 2005, por Brandão (2006). Os resultados indicaram que, dos profissionais formados em Física ou Astronomia, 74\% deles têm interesse ou já atuam na área de pesquisa. Apenas 13\% trabalham com popularização da Astronomia e 6\% lecionam em escolas públicas ou privadas.

O primeiro item analisado foi em relação à formação que possuem em nível de graduação. Verificamos que 175 deles possuem apenas uma graduação, e 12, duas ou mais. A distribuição, conforme os cursos, está exibida no Gráfico 1.

Investigamos, também, em que ano concluíram seus cursos de graduação, conforme Gráfico 2. 
Quem somos nós? Perfil da comunidade acadêmica ...

Gráfico 1. Formação em nível de graduação da comunidade acadêmica na Educação em Astronomia

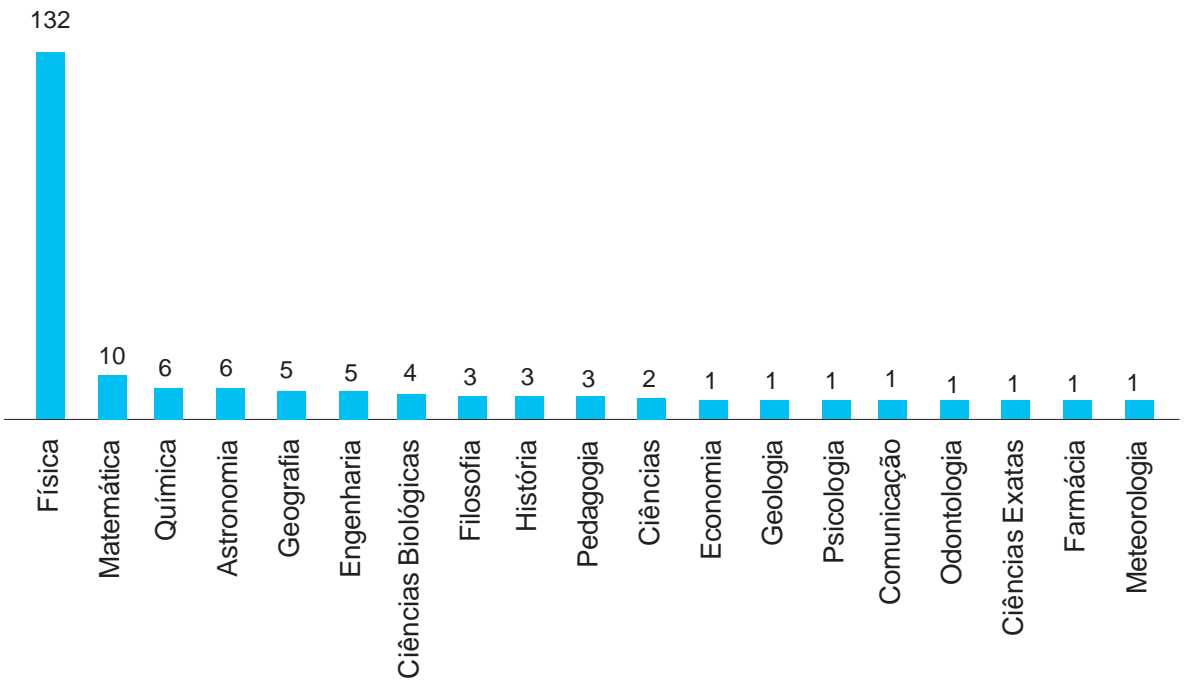

Fonte: elaborado pelos autores.

Gráfico 2. Ano de conclusão do curso de graduação da comunidade acadêmica na Educação em Astronomia

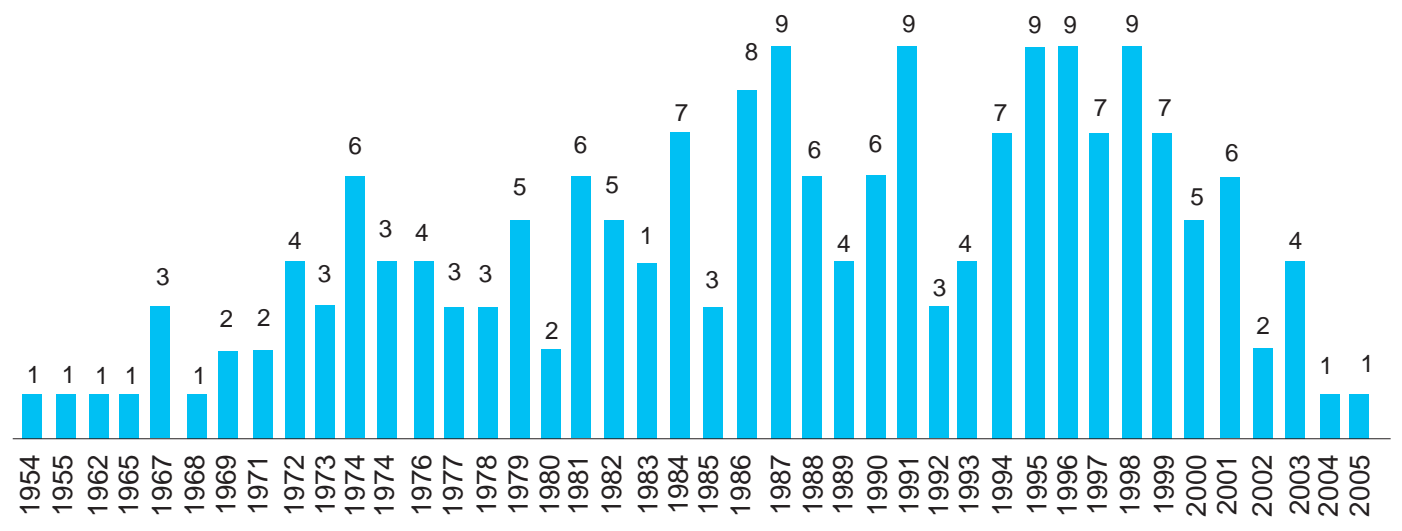

Fonte: elaborado pelos autores.

Além disso, investigamos em que região do país tais cursos foram concluídos, assim como a natureza da instituição frequentada, ou seja, se pública ou privada. Excluímos, de nosso grupo, três pesquisadores que cursaram graduação no exterior (Gráfico 3). 
Longhini, M. D.; Gomide, H. A.; Fernandes, T. C. D.

Gráfico 3. Regiões do país de conclusão do curso de graduação (A) e natureza das instituições (B)

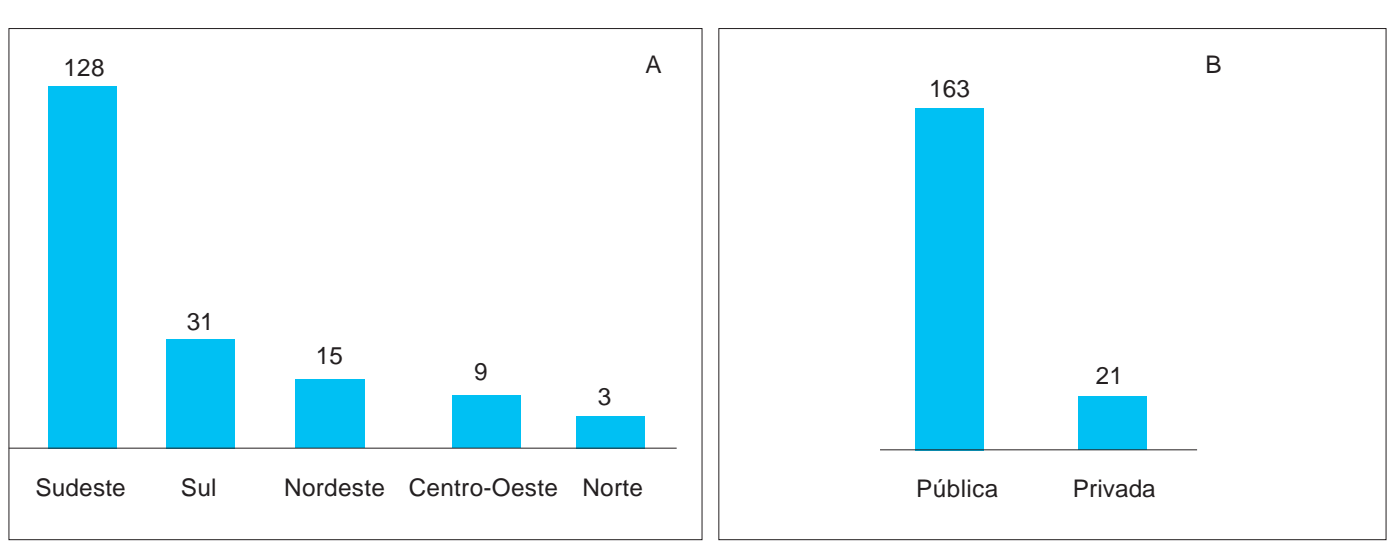

Fonte: elaborado pelos autores.

No que se refere à graduação, verificamos que se tratam de profissionais, em sua grande maioria, oriundos dos cursos de Física, egressos, majoritariamente, a partir da metade da década de 1980 até início de 2000, de instituições públicas, localizadas no Sudeste.

Quanto aos estudos de pós-graduação, dividimo-los em dois segmentos: mestrado e doutorado. De nosso público investigado, 12 não cursaram mestrado ou não o apresentaram na plataforma. Dos 175 profissionais que cursaram mestrado, o Gráfico 4 ilustra em que área isso ocorreu.

Gráfico 4. Áreas de concentração do mestrado da comunidade acadêmica na Educação em Astronomia

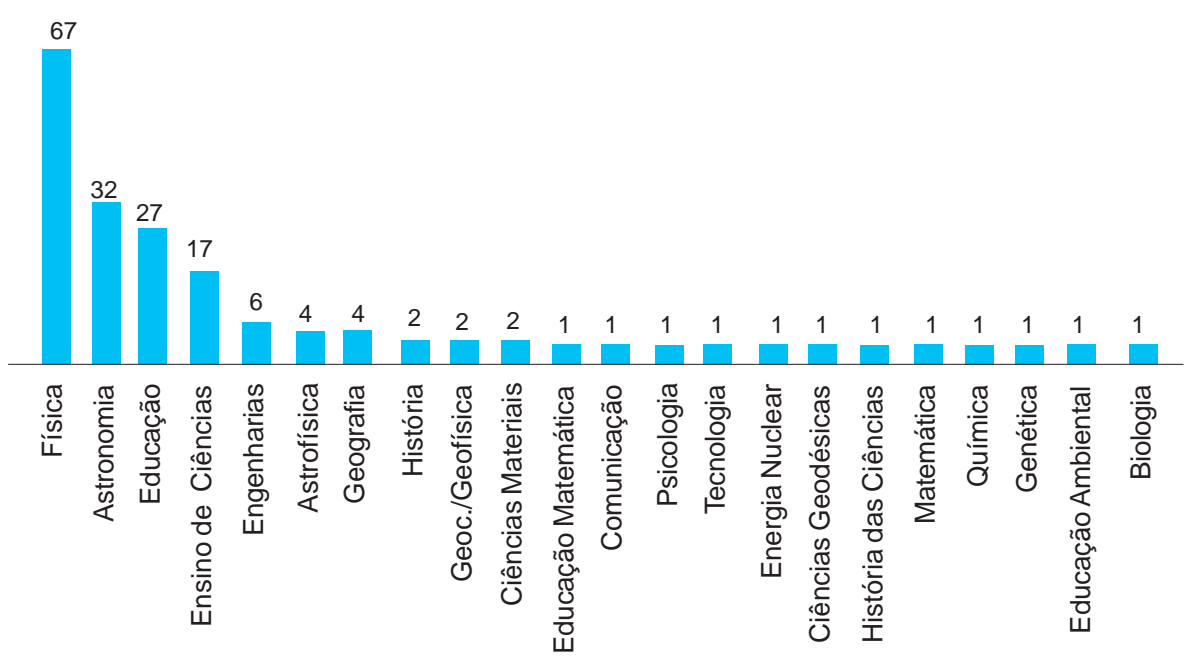

Fonte: elaborado pelos autores.

Ciênc. Educ., Bauru, v. 19, n. 3, p. 739-759, 2013 
Quem somos nós? Perfil da comunidade acadêmica ...

Investigamos, ainda, em que ano concluíram seus cursos de mestrado, conforme expressa o Gráfico 5 .

Gráfico 5. Ano de conclusão do mestrado da comunidade acadêmica na Educação em Astronomia

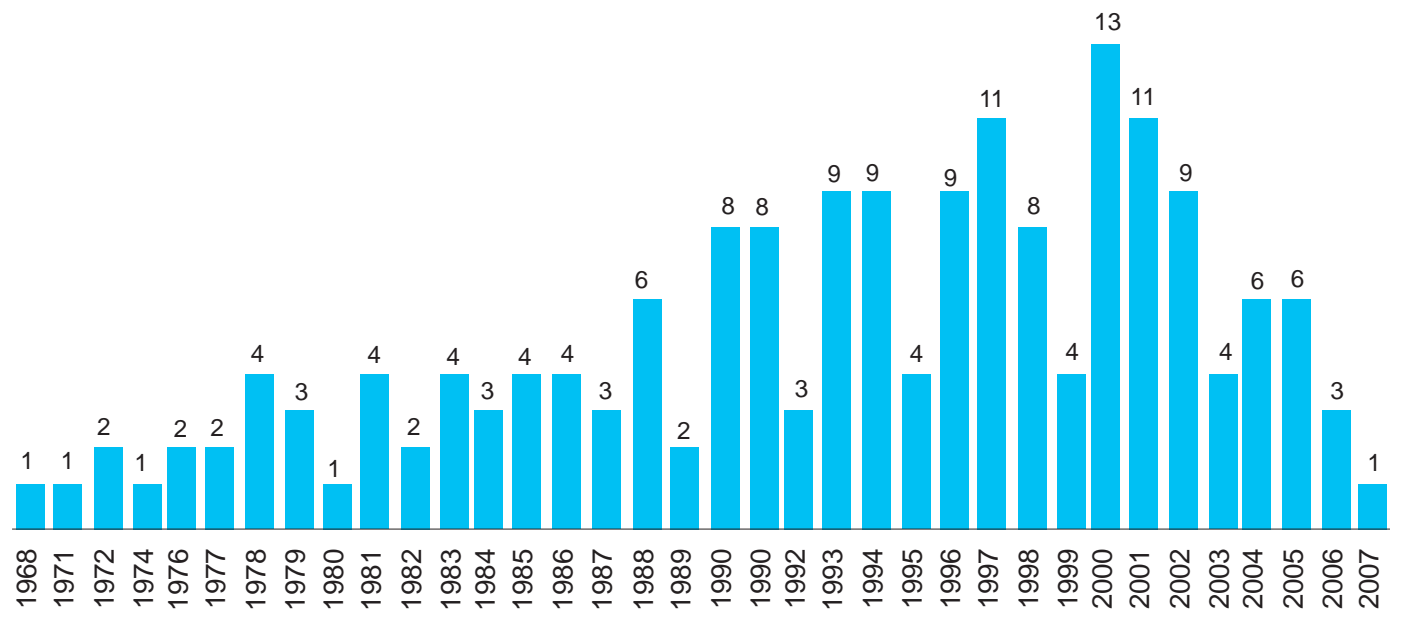

Fonte: elaborado pelos autores.

Também investigamos a região do país onde tais mestrados foram realizados, bem como a natureza da instituição onde os cursos estão alocados. Constatamos que, dos 175 pesquisados, três cumpriram o curso de mestrado fora do país, não sendo quantificados, conforme revela o Gráfico 6.

Gráfico 6. Regiões do país de conclusão do curso de mestrado (A) e tipo de instituição (B)
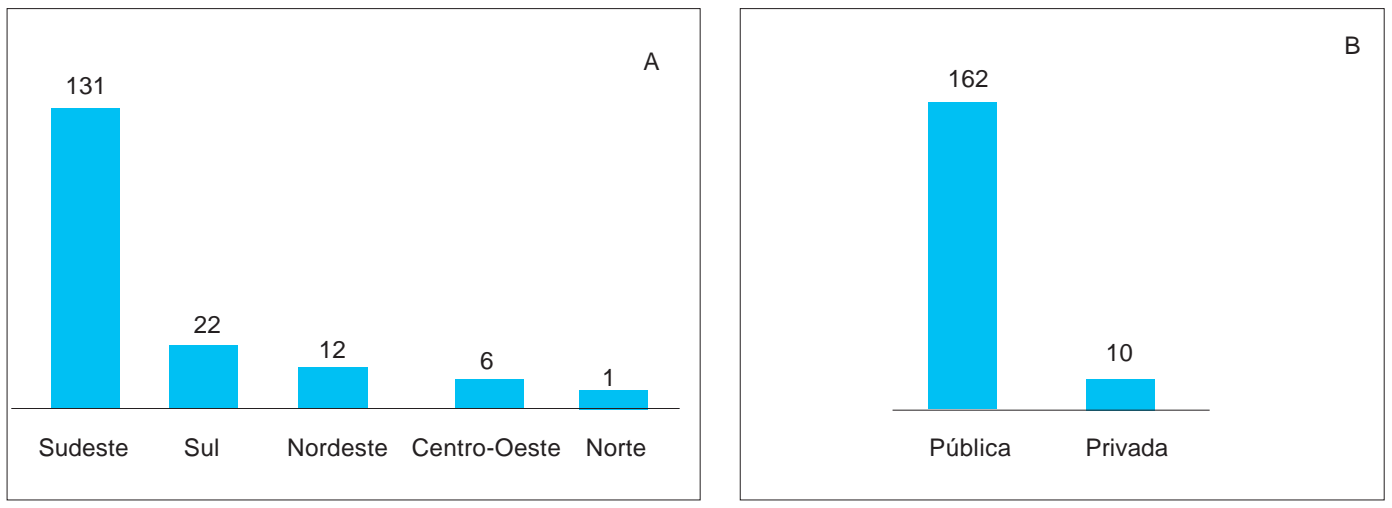

Fonte: elaborado pelos autores.

749 
Longhini, M. D.; Gomide, H. A.; Fernandes, T. C. D.

Uma análise panorâmica nos leva a perceber que a maioria dos investigados realizou seu mestrado, aproximadamente, cinco anos após a graduação, ou seja, há uma concentração maior no período que vai do final da década de 1980 até meados de 2000. A maior área de concentração é em Física, mas já se constatam mestrados em Astronomia, Educação e Ensino de Ciências; estes dois últimos, se somados, ultrapassam os de Astronomia. Ainda quanto à região, o perfil se mostra semelhante ao da graduação.

No que diz respeito ao doutorado, o Gráfico 7 nos expõe em que áreas eles foram desenvolvidos.

Gráfico 7. Áreas de concentração do doutorado da comunidade acadêmica na Educação em Astronomia

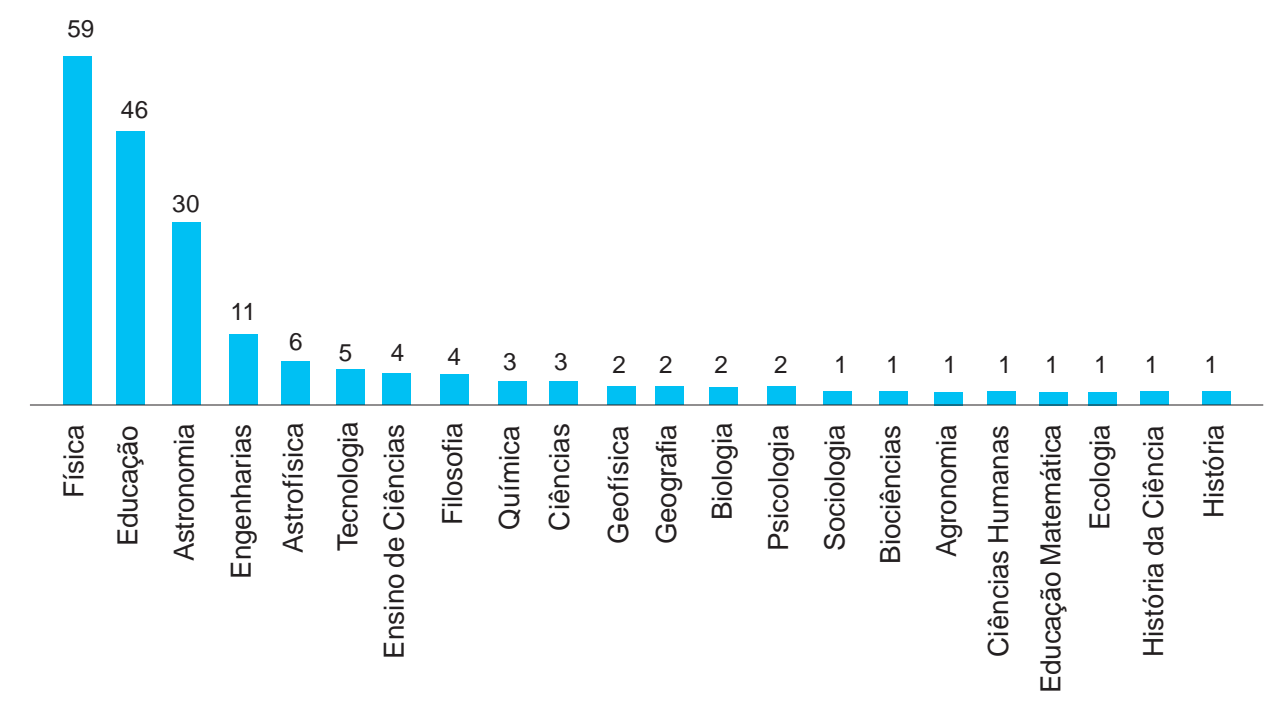

Fonte: elaborado pelos autores.

Da mesma maneira que no mestrado, investigamos em que ano concluíram seus cursos de doutorado. Dos 187 pesquisadores selecionados, um não mencionou, na plataforma, o ano de conclusão deste curso, conforme nos revela o Gráfico 8.

Também pesquisamos a região do país onde tais cursos de doutorado foram realizados, assim como a natureza da instituição onde eles estão alocados, excetuando-se 14 pesquisadores, que realizam seus estudos no exterior, e um que não mencionou tais informações na plataforma (Gráfico 9).

Novamente, a análise indica o deslocamento temporal do grupo majoritário, evidenciando uma tendência de a maioria ter concluído o doutorado entre a segunda metade da década de 1990 até o final da metade da década de 2010. Quanto às áreas, apesar da marcante presença da Física, verificamos aumento da área de Educação. A região de destaque continua o Sudeste, assim como as instituições públicas respondendo pela maioria dos programas. 
Quem somos nós? Perfil da comunidade acadêmica ...

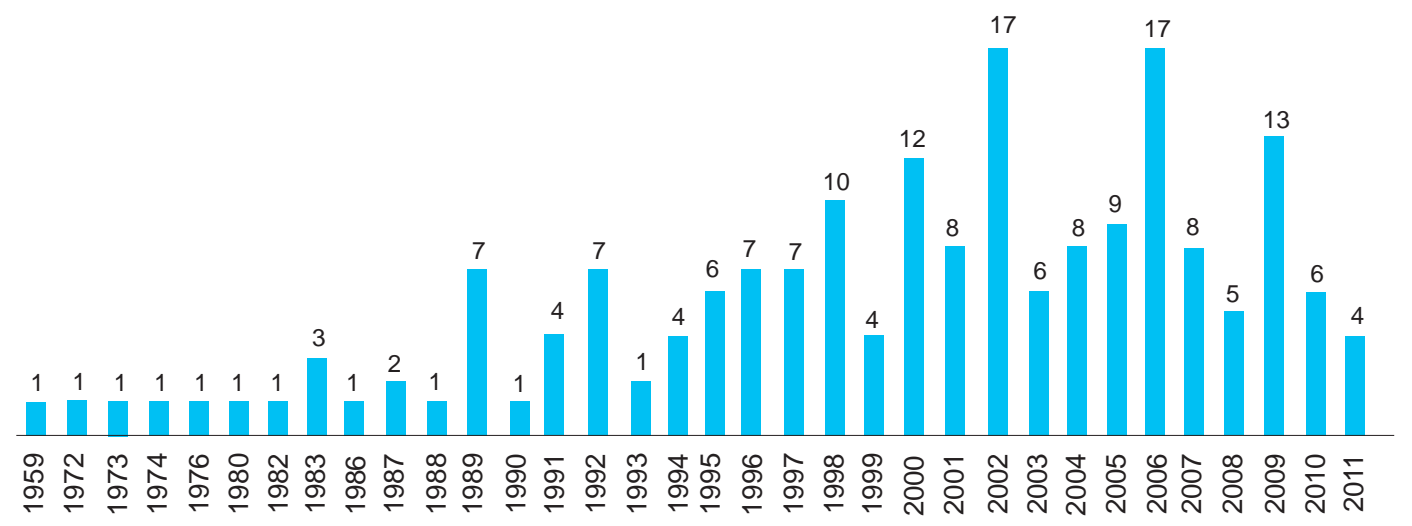

Fonte: elaborado pelos autores.

Gráfico 9. Regiões do país de conclusão do curso de doutorado (A) e natureza das instituições (B)
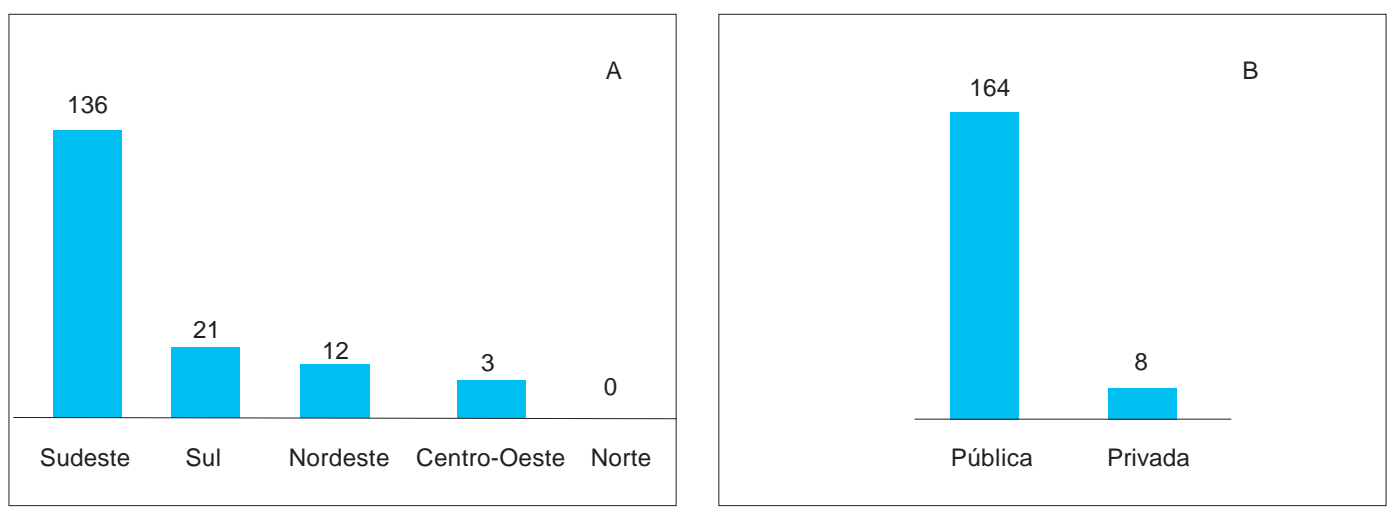

Fonte: elaborado pelos autores.

Esse resultado parece ir na direção dos dados de Iachel e Nardi (2010), quando revelam o interesse da área de Educação e Ensino de Ciências pelo Ensino de Astronomia. Além disso, o período de aumento no número de doutorados aproxima-se do incremento de teses e dissertações, ou seja, segunda metade de 1990, como afirmam Bretones e Megid Neto (2005). Também, conforme os mesmos autores, a prevalência de trabalhos concluídos se dá na região Sudeste e em instituições públicas. 
Longhini, M. D.; Gomide, H. A.; Fernandes, T. C. D.

Ao adentrar o campo da atuação profissional, observarmos que, dos 187 pesquisadores selecionados, três se encontram no exterior, 11 possuem vinculação com espaços que não são universidades, tais como centros de ciência, observatórios, museus, os quais são, em sua maioria, espaços públicos e localizados no Sudeste, conforme também apontam Linhares e Nascimento (2009). Isso demonstra que a vinculação profissional do grupo selecionado está fortemente relacionada às universidades. A distribuição de todas as instituições por região e a sua natureza estão indicadas no Gráfico 10.

Gráfico 10. Região do país onde atuam profissionalmente (A) e tipo de instituição (B)
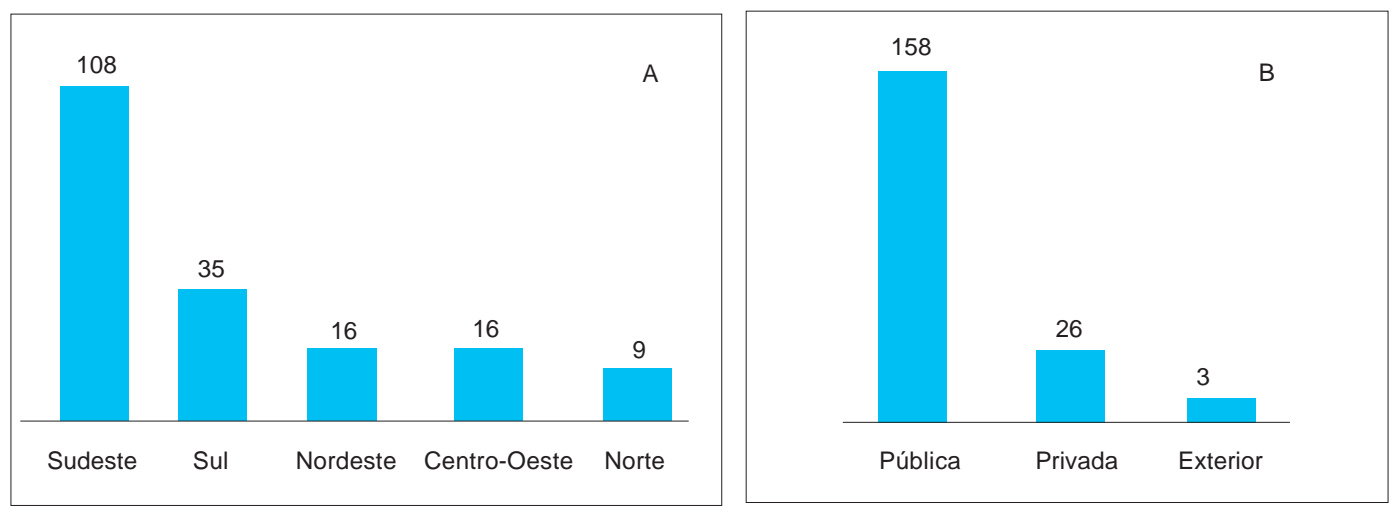

Fonte: elaborado pelos autores.

A análise nos permite inferir que se trata de profissionais que, em sua maioria, realizam sua formação na região Sudeste e em instituições públicas, e nelas acabam atuando profissionalmente.

No campo das atividades acadêmicas que realizam em suas instituições, dos 187 selecionados, 105 possuem algum tipo de projeto, seja em andamento ou concluído. Destes, 65 profissionais só possuem projetos de extensão; 20, só de pesquisa, e 20, tanto de extensão quanto de pesquisa.

Daqueles que exclusivamente desenvolvem projetos de extensão, investigamos qual seu perfil acadêmico, exposto no Gráfico 11.

Da mesma maneira, investigamos o perfil acadêmico daqueles que possuem projetos de pesquisa em Educação em Astronomia, demonstrado no Gráfico 12.

Os Gráficos 11 e 12 registram que o profissional que, em sua maioria, é o graduado em Física, com mestrado e doutorado também em Física ou Astronomia, realiza ou realizou atividades na Educação em Astronomia no campo da extensão, geralmente, na forma de projetos de divulgação científica. Por outro lado, o profissional que desenvolve pesquisas no campo da Educação em Astronomia é, em sua maioria, o graduado em Física, mestre em Física e Astronomia, porém, há envolvimento majoritário dos doutores em Educação. 
Quem somos nós? Perfil da comunidade acadêmica ...

Gráfico 11. Perfil acadêmico (graduação - A, mestrado - B e doutorado - C) daqueles que atuam somente em projetos de extensão na Educação em Astronomia.
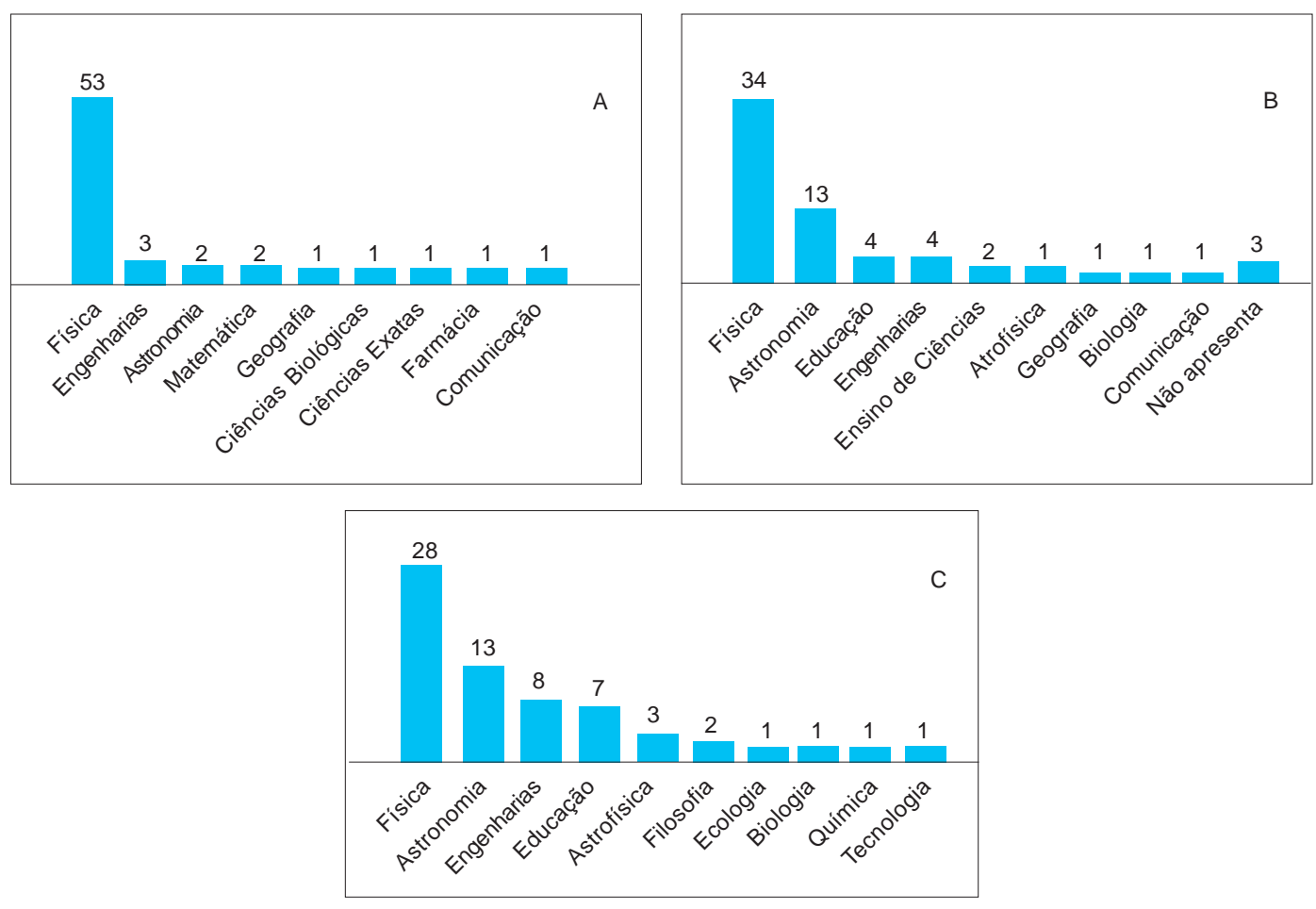

Fonte: elaborado pelos autores.

Gráfico 12. Perfil acadêmico (graduação - A, mestrado - B, e doutorado - C) daqueles que atuam em projetos de pesquisa na Educação em Astronomia
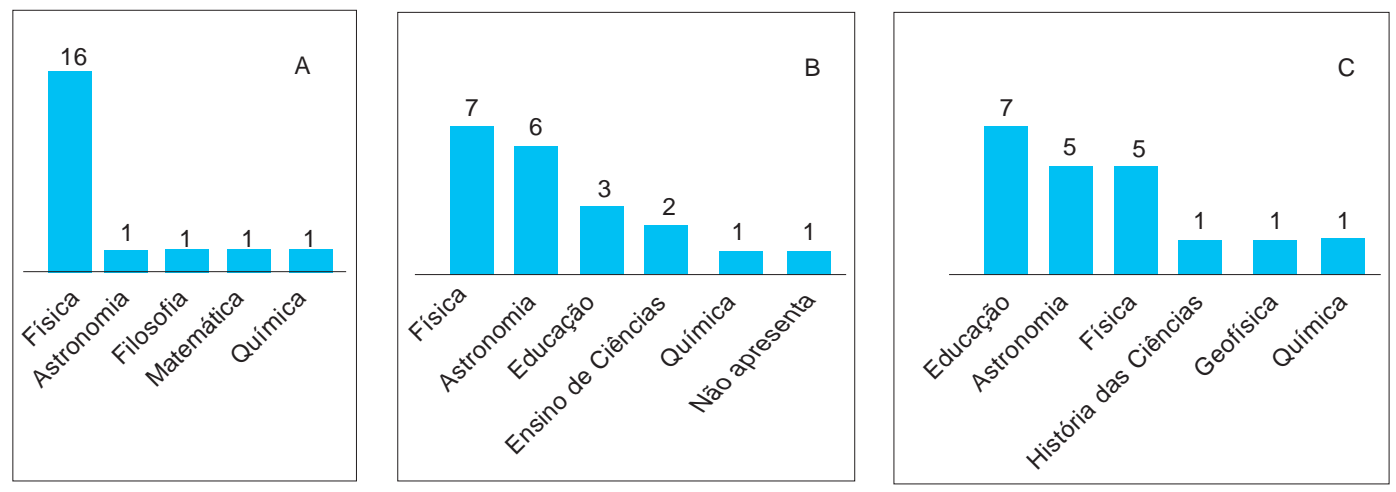

Fonte: elaborado pelos autores. 
Longhini, M. D.; Gomide, H. A.; Fernandes, T. C. D.

Quanto à produção bibliográfica em periódicos e livros, dos 187 analisados, noventa apresentam algum tipo. Além disso, 44 orientam ou orientaram iniciação científica em temáticas afins, assim como 48 atuam ou atuaram na pós-graduação stricto sensu, na orientação de mestrados e/ou doutorados. O Gráfico 13 revela o perfil do profissional que possui produção bibliográfica, e o 14, daqueles que atuam na pós-graduação.

Os gráficos 13 e 14 evidenciaram um perfil similar ao dos profissionais que possuem projetos de pesquisa em Educação em Astronomia, ou seja, há prevalência de doutores em Educação, o que pode indicar que tais projetos se desdobram em orientações na pós-graduação e produção bibliográfica na área. O mesmo perfil corrobora dados de Iachel e Nardi (2010), que revelam a inserção de pesquisadores da área de Educação e Ensino de Ciências na publicação de artigos relacionados à Astronomia.

Quanto à presença marcante de profissionais da Física, Marrone Júnior e Trevisan (2009) afirmam que a articulação entre esta área e a Astronomia é evidenciada por meio de artigos que apresentam trabalhos nos quais a Física é aplicada à Astronomia e a Astronomia ao ensino de Física. Segundo os autores, parece ainda tênue a linha que separa o Ensino de Física do de Astronomia.

Gráfico 13. Perfil acadêmico (graduação - A, mestrado - B, e doutorado - C) daqueles que possuem produção bibliográfica na Educação em Astronomia
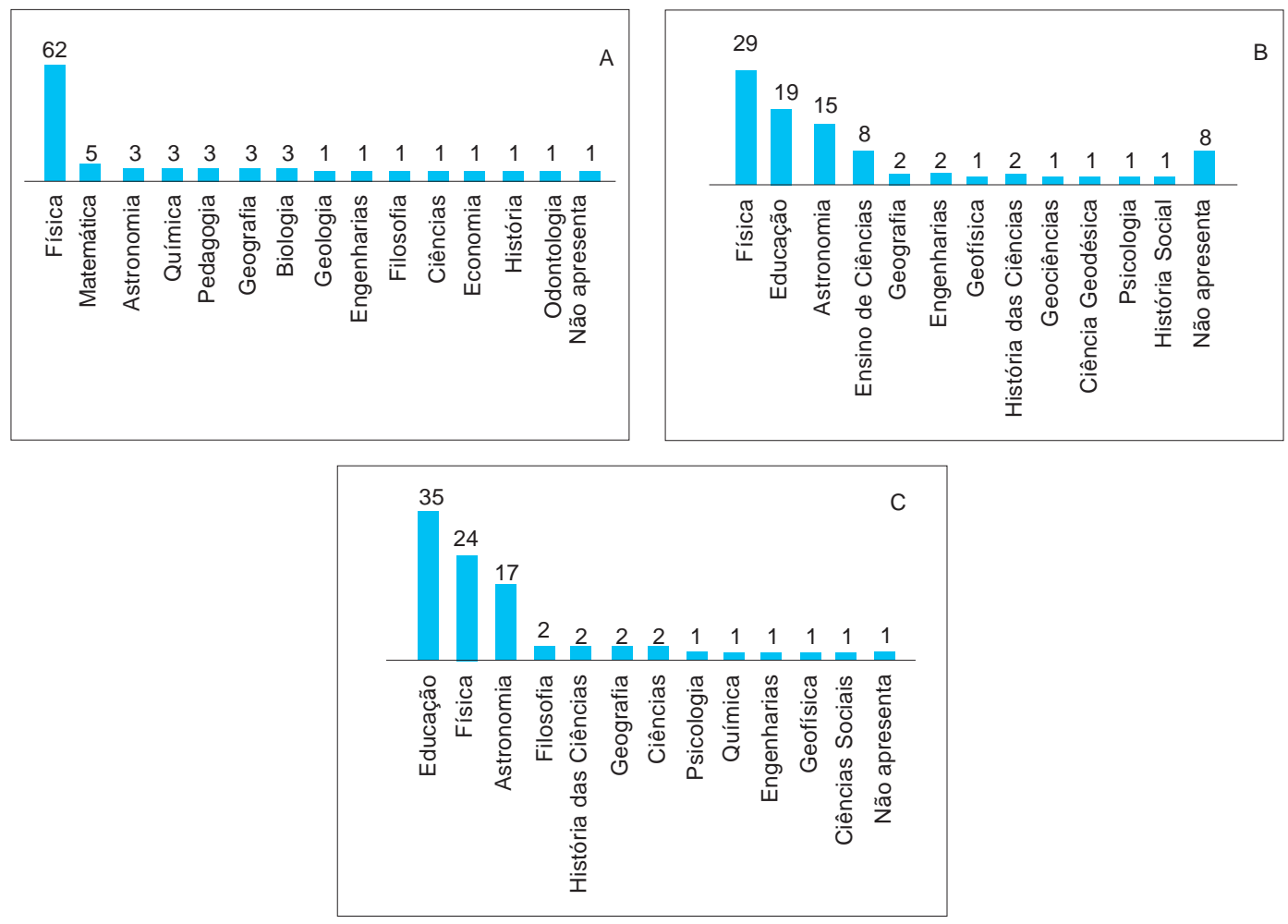

Fonte: elaborado pelos autores. 
Quem somos nós? Perfil da comunidade acadêmica ...

Gráfico 14. Perfil acadêmico (graduação - A, mestrado - B, e doutorado - C) daqueles que orientam mestrado e/ou doutorado na Educação em Astronomia
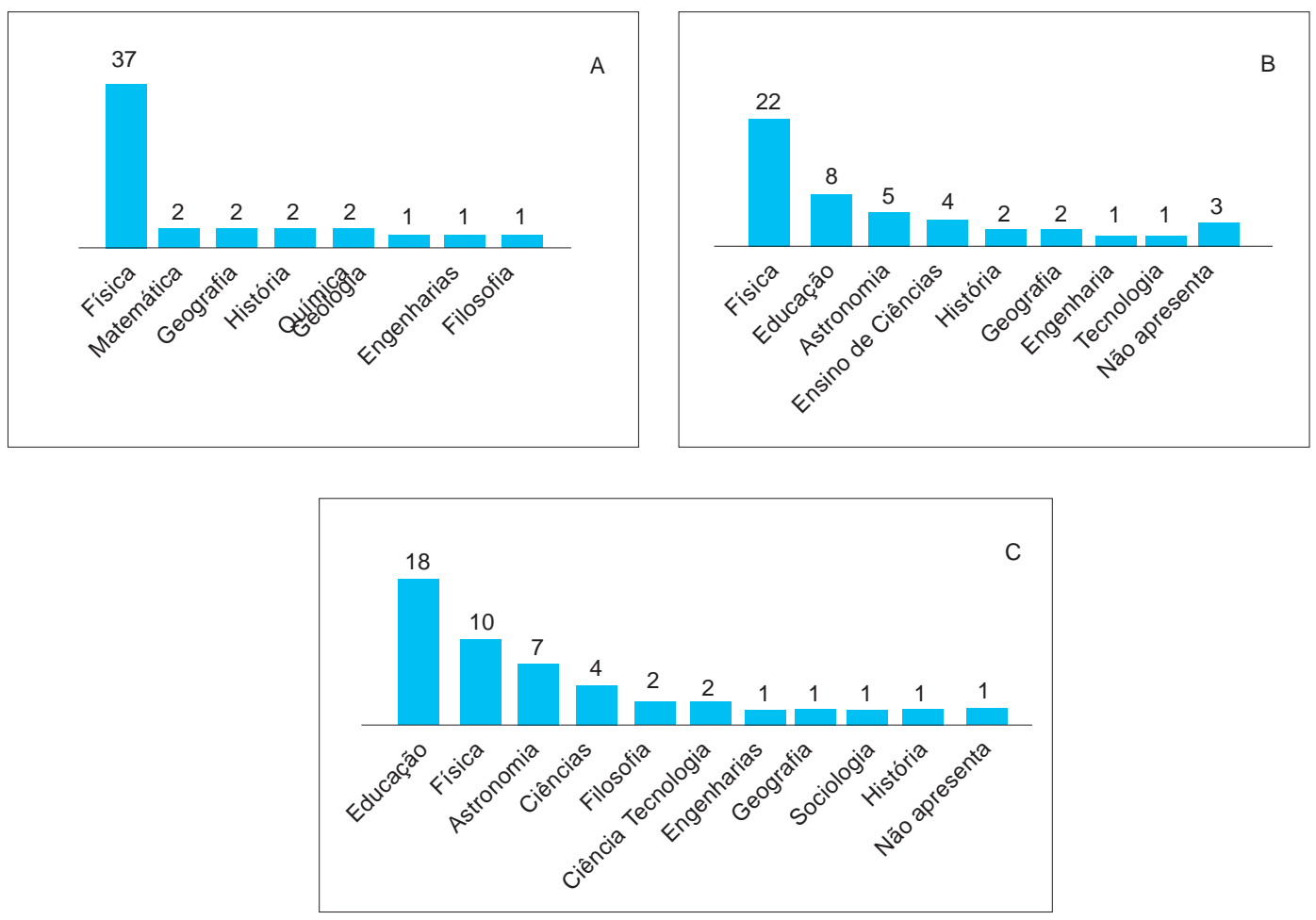

Fonte: elaborado pelos autores.

\section{Considerações finais}

A pesquisa realizada, assim como o retrospecto histórico descrito, reforçam que a Astronomia, no Brasil, apesar de presente desde os primórdios da nação, ainda é uma ciência com recente crescimento. Especificamente, na Educação em Astronomia, percebemos um movimento de fortalecimento dos trabalhos na área, que vêm no bojo da realização de eventos, projetos de pesquisa, publicação de artigos e livros, e surgimento de periódicos.

Também evidenciamos que a grande parte dos profissionais envolvidos é oriunda de cursos de Física. Tal dado leva a três considerações: a primeira é a de que, devido ao reduzido número de cursos de graduação em Astronomia, a comunidade interessada na área inicia seus estudos na Física e parte para a pós-graduação em Astronomia, que dispõe de maior diversidade de instituições que a oferecem. A segunda é a de que os estudantes descobrem seu interesse em Astronomia durante os cursos de graduação em Física, quando estes ofertam algum estudo nesta área. Por fim, a terceira é a de que, quando analisado o público que envereda para os 
Longhini, M. D.; Gomide, H. A.; Fernandes, T. C. D.

estudos de pós-graduação em Educação ou Ensino de Ciências, há também predominância, no cenário nacional, daqueles oriundos dos cursos de graduação em Física, como assegura Nardi (2007).

No que diz respeito à formação em pós-graduação, o estudo revelou que isso vem ocorrendo, notadamente, a partir da década de 1970, quando os programas começam a se consolidar no país, inclusive os da área de Educação, com a primeira tese concluída em 1972, conforme afirma Megid Neto (2007).

A distribuição dos pesquisadores pelo território nacional evidencia a concentração no Sudeste, tanto como região de formação, quanto de atuação profissional, a qual ocorre, em sua grande maioria, em universidades.

Também identificamos que aqueles que possuem formação acadêmica voltada para a graduação em Física e pós-graduação também nesta área, além da Astronomia, mostram maior envolvimento em atividades no âmbito da extensão no que se refere ao campo específico da Educação em Astronomia. Por outro lado, as atividades voltadas à pesquisa, orientação e pósgraduação, nesse campo específico de estudo, são realizadas por aqueles com perfil mais voltado para a pós-graduação em Educação, apesar da presença ainda marcante dos pós-graduados em Física e Astronomia.

Retomando a questão que dá título a este artigo, podemos dizer que "nós" não somos a maior parte dentre aqueles que possuem vínculo com a Astronomia, segundo a Plataforma Lattes, mas respondemos por $17 \%$ deles; que temos perfis variados, apesar de marcadamente influenciados pela Física; que atuamos em todas as regiões do país, apesar de preponderantemente no Sudeste; que trabalhamos em espaços de educação formal e não formal, apesar de, majoritariamente, em universidades; e que realizamos pesquisa e extensão, apesar de grupos com perfis diferentes se destacarem em cada uma das frentes. Essa é a comunidade que, atualmente, atua na Educação em Astronomia no Brasil.

\section{Agradecimentos}

Ao apoio de Luana Mendes Xavier e Natalina dos Reis Silva, bolsistas de iniciação científica, na recuperação dos currículos.

\section{Referências}

AMARAL, P. $O$ ensino de astronomia nas séries finais do ensino fundamental: uma proposta de material didático de apoio ao professor. 2008, 101 f. Dissertação (Mestrado em Ensino de Ciências) - Universidade de Brasília, Brasília, 2008.

ARANY-PRADO, L.; GONZALEZ, E. A. M. 30 anos do curso de graduação em astronomia da UFRJ: uma análise crítica. Anuário do Instituto de Geociências, Rio de Janeiro, v. 20, p. 215-232, 1997. 
Quem somos nós? Perfil da comunidade acadêmica ...

BARBOSA, S. F. F.; DAL SASSO, G. T. M.; BERNS, I. Enfermagem e tecnologia: análise dos grupos de pesquisa cadastrados na Plataforma Lattes do CNPq. Texto \& Contexto Enfermagem, Florianópolis, v. 18, n. 3, p. 443-448, 2009.

BRANDÃO, H. Censo astronômico 2005. Revista Macrocosmo, ano 4, n. 37, p. 2-6, dez. 2006. Disponível em: <http://www.revistamacrocosmo.com/edicoes/download/pdf/ macrocosmo37.pdf>. Acesso em: 02 ago. 2011.

BRETONES, P. S.; MEGID NETO, J. Tendências de teses e dissertações sobre ensino de astronomia no Brasil. Boletim da Sociedade Astronômica Brasileira, São José dos Campos, v. 24, n. 2, p. 35-43, 2005.

- A educação em astronomia nos trabalhos das reuniões anuais da Sociedade Astronômica Brasileira. Boletim da Sociedade Astronômica Brasileira, São José dos Campos, v. 26, n. 2, p. 55-72, 2006.

CASTRO, E. S. B.; PAVANI, D. B.; ALVES, V. M. A produção em ensino de astronomia nos últimos quinze anos. In: SIMPÓSIO NACIONAL DE ENSINO DE FÍSICA, 18., 2009, Vitória. Anais... Disponível em: < http://www.sbf1.sbfisica.org.br/eventos/snef/ xviii/sys/resumos/T0697-1.pdf>. Acesso em: 02 ago. 2011.

CONSELHO NACIONAL DE DESENVOLVIMENTO CIENTÍFICO E TECNOLÓGICO. Portal CNPq. Disponível em: <http://www.cnpq.br/>. Acesso em: 03 ago. 2011.

DAMINELI, A. Curso de graduação em astronomia no IAG/USP. Supernovas: Boletim Brasileiro de Astronomia, São Paulo, n. 467, 26 jun. 2008. Disponível em: <http:// www.boletimsupernovas.com.br/>. Acesso em: 02 ago. 2011.

DAMINELI, A.; STEINER, J. (Org.). O fascínio do universo. São Paulo: Odysseus, 2010.

ELIAS, D. C. N.; AMARAL, L. H.; ARAÚJO, M. S. T. Criação de um espaço de aprendizagem significativa no planetário do parque Ibirapuera. Revista Brasileira de Pesquisa em Educação em Ciências, São Paulo, v. 7, n. 1, p. 1-15, 2007.

FARIA, R. P. et al. Fundamentos de astronomia. 3. ed. Campinas: Papirus, 1987.

IACHEL, G.; NARDI, R. Algumas tendências das publicações relacionadas à astronomia em periódicos brasileiros de ensino de física nas últimas décadas. Ensaio: Pesquisas em Ensino de Ciências, Belo Horizonte, v. 12, n. 2, p. 225-238, maio-ago., 2010.

LANE, J. Let's make science metrics more scientific. Nature, London, n. 464, p. 488-489, 25 Mar. 2010.

LANGHI, R. Um estudo exploratório para a inserção da astronomia na formação de professores dos anos iniciais do ensino fundamental. 2004. 240 f. Dissertação (Mestrado em Educação para a Ciência) - Faculdade de Ciências, Universidade Estadual Paulista, Bauru, 2004. 
Longhini, M. D.; Gomide, H. A.; Fernandes, T. C. D.

LANGHI, R.; NARDI, R. Ensino da astronomia no Brasil: educação formal, informal, não formal e divulgação científica. Revista Brasileira de Ensino de Física, São Paulo, v. 31, n. 4, p. 4402-1- 4402-10, 2009a.

. Educação em astronomia no Brasil: alguns recortes. In: SIMPÓSIO NACIONAL DE ENSINO DE FÍSICA, 18., 2009, Vitória. Anais... São Paulo: Sociedade Brasileira de Física, 2009b. Disponível em: <http://www.sbf1.sbfisica.org.br/eventos/snef/xviii/ > . Acesso em: 02 ago. 2011.

. O que dizem os pesquisadores brasileiros sobre as justificativas para o ensino de astronomia. In: ENCONTRO DE PESQUISA EM ENSINO DE FÍSICA, 13., 2011, Foz do Iguaçu. Atas... Disponível em: < http://www.sbf1.sbfisica.org.br/eventos/enf/2011/ sys/resumos/T1948-1.pdf>. Acesso em: 02 ago. 2011.

LINHARES, F. R. C.; NASCIMENTO, S. S. Espaços de divulgação de astronomia no Brasil: um mapeamento através da internet. In: ENCONTRO NACIONAL DE PESQUISA EM EDUCAÇÃO EM CIÊNCIAS, 7., 2009, Florianópolis. Caderno de resumos... Belo Horizonte: ABRAPEC, 2009. v. 1. p. 190-190.

LONGHINI, M. D. O universo em uma caixa: introdução ao estudo da astronomia na formação inicial de professores de física. Revista Latino-Americana de Educação em Astronomia - RELEA, São Carlos, n. 7, p. 31-42, 2009.

MARRONE JÚNIOR, J.; TREVISAN, R. H. Um perfil da pesquisa em ensino de astronomia no Brasil a partir da análise de periódicos de ensino de ciências. Caderno Brasileiro de Ensino de Física, Florianópolis, v. 26, n. 3, p. 547-574, dez. 2009.

MEGID NETO, J. Três décadas de pesquisas em educação em ciências: tendências de teses e dissertações (1972-2003). In: NARDI, R. (Org.). A pesquisa em ensino de ciências no Brasil: alguns recortes. São Paulo: Escrituras, 2007. p. 341-355.

MORAES, A. A astronomia no Brasil. São Paulo: USP, 1984.

NARDI, R. A área de ensino de ciências no Brasil: fatores que determinaram sua constituição e suas características segundo pesquisadores brasileiros. In: NARDI, R. (Org.). A pesquisa em ensino de ciências no Brasil: alguns recortes. São Paulo: Escrituras, 2007. p. 357-412.

PEPE, V. L. E. et al. A produção científica e grupos de pesquisa sobre vigilância sanitária no CNPq. Ciência \& Saúde Coletiva, Rio de Janeiro, v. 15, n. 3, p. 3341-3350, 2010.

PLATAFORMA Lattes. Disponível em:<http://lattes.cnpq.br/>. Acesso em: 03 ago. 2011.

SILVA, F. M. et al. Reflexões sobre o uso da Plataforma Lattes como um instrumento de resgate da memória do Tribunal de Justiça de Pernambuco. Documentação e Memória TJPE, Recife, v. 1, n. 2, p. 21-32, jan./dez. 2009.

SILVA, F. M.; SMIT, J. W. Organização da informação em sistemas eletrônicos abertos de informação científica \& tecnológica: análise da Plataforma Lattes. Perspectivas em

Ciência da Informação, Belo Horizonte, v. 14, n. 1, p. 77-98, 2009. 
Quem somos nós? Perfil da comunidade acadêmica ...

VALENTE, J. A. S. A construção de conceitos relacionados com os movimentos Terra-Lua-Sol por alunos da E.J.A. à luz da teoria histórico-cultural. 2007.

Dissertação (Mestrado em Educação em Ciências e Matemáticas) - Universidade Federal do Pará, Belém, 2007.

VARELLA, I. G.; OLIVEIRA, P. D. C. F. Observatórios do Brasil. Uranometria Nova, dez. 2010. Disponível em < http://www.uranometrianova.pro.br/observatorios/ obsbrasil.htm>. Acesso em: 03 jul. 2012.

Planetários do Brasil. Uranometria Nova, abr. 2012. Disponível em: <http:// www.uranometrianova.pro.br/planetarios/planbrasil.htm>. Acesso em: 03 jul. 2012. 